\title{
AquaLase VERSUS NeoSoniX - A COMPARISON STUDY
}

\author{
Nada Jiraskova*, Pavel Rozsival, Jana Kadlecova, Jana Nekolova, Jana Pozlerova, \\ Zlatica Dubravska
}

\author{
Department of Ophthalmology, University Hospital, Hradec Kralove, Czech Republic \\ * Reprint requests to Assoc. Prof. Nada Jiraskova, MD, PhD, Department of Ophthalmology, University Hospital, Sokolska \\ 581, 50005 Hradec Kralove, Czech Republic \\ e-mail:jirasnad@fnhk.cz
}

Received: August 21, 2007; Accepted: September 30, 2007

Key words: Phacoemulsification/AquaLase/Pachymetry/Endothelial cell density

\begin{abstract}
Aims: To compare the metrics and surgical outcome when using Infiniti AquaLase and NeoSoniX cataract removal modalities.

Methods: This prospective clinical study involved 50 patients with bilateral cataracts and lens removal using AquaLase in the right eye and NeoSoniX in the left eye. Best corrected visual acuity (BCVA), endothelial cell density and pachymetry were evaluted pre- and postoperatively. Statistical analysis was performed using the Wilcoxon SignedRank Test.

Results: Preoperative mean pachymetry was $569 \pm 31 \mu$ in the right eye (RE) and $560 \pm 37 \mu$ in the left eye (LE), mean endothelial cell density $2744 \pm 418$ cells $/ \mathrm{mm}^{2}(\mathrm{RE})$ and $2730 \pm 472 \mathrm{cells} / \mathrm{mm}^{2}$ (LE). One week after operation pachymetry was $576 \pm 52 \mu(\mathrm{RE})$ and $583 \pm 72 \mu(\mathrm{LE})$ and endothelial cell density $2388 \pm 586 \mathrm{cells} / \mathrm{mm}^{2}(\mathrm{RE})$ and $2463 \pm 615$ cells $/ \mathrm{mm}^{2}$ (LE). One month after surgery pachymetry was $556 \pm 43 \mu$ (RE) and $559 \pm 44 \mu$ (LE) and endothelial cell density $2368 \pm 52$ cells $/ \mathrm{mm}^{2}(\mathrm{RE})$ and $2495 \pm 548$ cells $/ \mathrm{mm}^{2}$ (LE). BCVA improved in all eyes and was 0.8 or better on the first postoperative day.
\end{abstract}

Conclusions: Both the NeosoniX and AquaLase minimize intraoperative damage to ocular structures.

\section{INTRODUCTION}

Phacoemulsification has become the current preferred procedure for cataract removal ${ }^{1-4}$. Continual improvements in new technologies and techniques allow cataract surgery to be performed even more safely and efficiently ${ }^{5-7}$. The quest for lens extraction involving reduced intraocular energy has been fulfilled with power modulations and supplemental energy sources, with improved outcomes ${ }^{8-10}$.

Conventional ultrasonic (US) phacoemulsification is created in a handpiece when power is applied to piezoelectric crystals which convert the electrical energy into mechanical vibrations of the phaco needle. The phaco needle tip is used to emulsify the lens material at ultrasonic frequencies generally between $25 \mathrm{KHz}$ and $62 \mathrm{KHz}$, which creates both thermal and cavitational energy with potential damage to the cornea. NeoSoniX handpiece delivers oscillatory sonic and axial ultrasonic energy separately or in combination. The phaco tip has a variable rotational oscillation up to 2 degrees at an approximate frequency of $100 \mathrm{~Hz}$. This lower frequency produces no significant thermal energy and thus minimizes the risk for thermal injury. Previous studies ${ }^{11}$ suggest that US coupled with oscillatory motion is more efficient than just applying axial energy alone.

The AquaLase liquefaction device is one of the most recent innovations in phacoemulsification. Warmed pulses $\left(57^{\circ} \mathrm{C}\right)$ of balanced salt solution (BSS) are used to strain and dissolve the lens for aspiration. Within the AquaLase handpiece, $4 \mu \mathrm{L}$ fluid pulses are generated as current passes between electrodes. These pulses then travel from the handpiece into the tip of the instrument and eventually into the eye. The fluid pulses pass through a channel in the outer sleeve of the tip and exit through a single small opening located in the lumen of the polymer application tip near its distal end. Aspiration of the liquefied lens material occurs through the central lumen of the tip. The BSS pulses are delivered at a maximum rate of $50 \mathrm{~Hz}$, and the magnitude of the pulses can be linearly controlled by foot-pedal depression.

The purpose of this study was to compare the metrics and surgical outcome using AquaLase and NeoSoniX cataract removal modalities.

\section{MATERIALS AND METHODS}

This prospective clinical study included 50 patients with bilateral lens opacification scheduled for cataract surgery at the Department of Ophthalmology, University Hospital, Hradec Králové. Patients were selected from the waiting list. To be eligible for the study, both eyes had to have cataract preferably with similar grades of density. Patients with ocular surface disease, endothelial or stromal corneal dystrophies as well as corneal scars, macular degeneration or any conditions that would affect postop- 


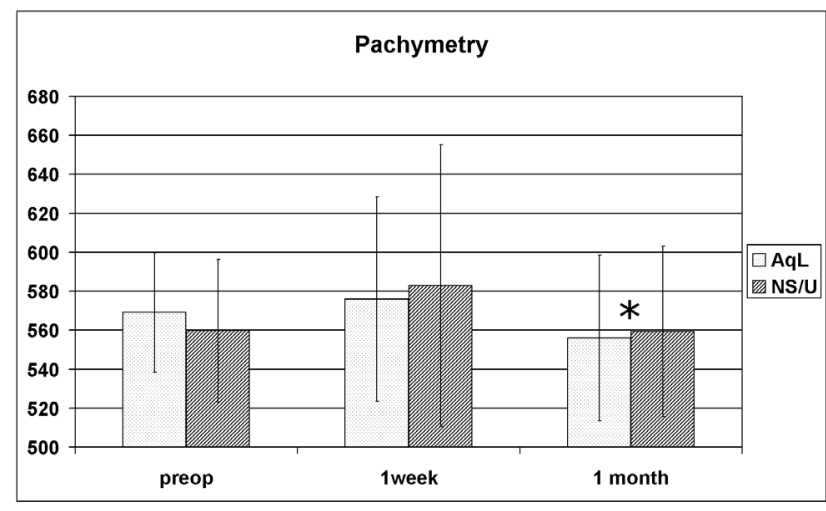

Fig. 1. Mean pachymetry values and standard deviations in AquaLase and NeoSoniX groups preoperatively, 1 week and 1 month after operation. At one month follow-up there was a statistically significant difference between both groups in the postoperative changes (difference between postoperative and preoperative values) *.

erative visual recovery were excluded. The purpose, procedures, and responsibilities were explained to all potential participant, and informed consent was obtained.

Before surgery, a complete eye examination was performed. Best corrected distance visual acuity was measured using Snellen optotypes, endothelial cell density and pachymetry using specular microscope CONAN NONCON ROBO. Cataracts were graded clinically on the basis of their hardness according to the Buratto classification $^{2}$ (grade 1-5 scale). Patients with very hard nucleus (grade 5 - brown or black hard-rock cataracts) were not included in this study. Surgery was performed by two surgeons (NJ, PR), one surgeon per patient (both eyes). Phacoemulsification was performed under topical anesthesia via $3.0 \mathrm{~mm}$ limbal incision using AquaLase in the right eye and NeoSoniX in the left eye. The standard AquaLase soft polymer needle (flared at the tip) with a 1.1 inner diameter and a $1.32 \mathrm{~mm}$ outer diameter was used in the case of AquaLase procedures and a 30-degree round $1.1 \mathrm{~mm}$ flared ABS tip in the cases of NeoSoniX use. The phaco settings were modified for each cataract grade on both lens removal modalities (Table 1 and 2). AcrySof Single Piece IOLs (Alcon) were implanted in the bag through a Monarch II injector system. All patients received topical tobramycin $3.0 \mathrm{mg} / \mathrm{mL}$ and dexamethasone $1.0 \mathrm{mg} / \mathrm{mL}\left(\right.$ Tobradex $^{\circledR}$ ) five times daily for 2 weeks postoperatively, followed by dexamethasone $1,0 \mathrm{mg} / \mathrm{mL}$ (Dexamethason $^{\circledR}$ ) three times daily for 2 weeks.

Best corrected Snellen visual acuity at a distance was measured on the first postoperative day, 1 week and 1 month after surgery. Endothelial cell density and pachymetry were evaluated 1 week and 1 month after surgery. The mean values of pachymetry and endotellial cell density were calculated, as well as standard deviation (SD) of the means in each group. Statistical analysis of the postoperative changes of pachymetry (difference between the postoperative and preoperative values) and ECC (difference between the preoperative and postoperative values) was

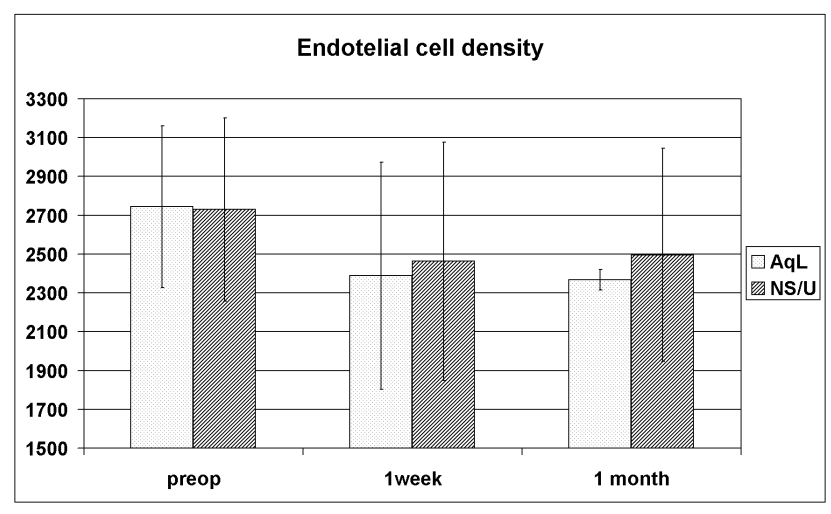

Fig. 2. Mean endothelial cell density values and standard deviations in AquaLase and NeoSoniX groups preoperativelly, 1 week and 1 month after operation

performed using the Wilcoxon Signed-Rank Test, which compares, pair by pair, the rank values of the selected variables, and displays the count of positive and negative differences.

\section{RESULTS}

\section{Phacoemulsifications Metrics}

The mean AquaLase time was $1.04 \pm 1.16$ seconds. Number of pulses varied from 0 (soft lens where only irigation/aspiration using high vacuum was employed) to 5280 (hard cataract grade 4). The median value was 975 pulses, the mean value was $1353 \pm 1407$ pulses. Fixed flow and vacuum were used in all AquaLase cases, the dynamic rise was chosen 2 or 3 (Table 1). The peak vaccum varied from $141 \mathrm{mmHg}$ to $729 \mathrm{mmHg}$, median 545, mean 520 $\pm 95 \mathrm{~mm} \mathrm{Hg}$.

In the NeoSoniX phacoemulsifications the mean phaco power was $6.9 \pm 4.7 \%$ and the mean effective phaco time was $7.14 \pm 5.8$ seconds. Fixed flow and vacuum were used in all eyes and the dynamic rise was 3 or 4 (table 2). The peak vacuum varied from 380 to $696 \mathrm{mmHg}$, median 549.5, mean $545.7 \pm 62.1 \mathrm{mmHg}$.

\section{Surgical Outcomes}

Preoperative mean pachymetry was $569 \pm 31 \mu$ in the right eye (RE) and $560 \pm 37 \mu$ in the left eye (LE), mean endothelial cell density $2744 \pm 418$ cells $/ \mathrm{mm}^{2}(\mathrm{RE})$ and $2730 \pm 472$ cells $/ \mathrm{mm}^{2}$ (LE). One week after operation pachymetry was $576 \pm 52 \mu(\mathrm{RE})$ and $583 \pm 72 \mu(\mathrm{LE})$ and endothelial cell density $2388 \pm 586$ cells $/ \mathrm{mm}^{2}(\mathrm{RE})$ and $2463 \pm 615$ cells $/ \mathrm{mm}^{2}$ (LE). One month after surgery pachymetry was $556 \pm 43 \mu(\mathrm{RE})$ and $559 \pm 44 \mu$ (LE) and endothelial cell density $2368 \pm 52$ cells $/ \mathrm{mm}^{2}(\mathrm{RE})$ and $2495 \pm 548$ cells $/ \mathrm{mm}^{2}$ (LE) (Figures 1 and 2 ). The differences in postoperative changes in pachymetry and ECC between AquaLase and NeosoniX groups were not statistically significant, except for pachymetry at 1 month follow-up where the results were better in the AquaLase group. 
Table 1. AquaLase settings for each cataract grade

\begin{tabular}{|c|c|c|c|c|}
\hline Grade & Linear Magnitude & Burst & Fluidics - fixed flow \& vacuum & Dynamic Rise \\
\hline 1 & $60 \%$ @ 40pps & $50 \%$ & $96 \mathrm{~cm}, 36 \mathrm{cc} / \mathrm{min}, 500 \mathrm{mmHg}$ & 2 \\
\hline 2 & $80 \%$ @ 50pps & $50 \%$ & $100 \mathrm{~cm}, 40 \mathrm{cc} / \mathrm{min}, 550 \mathrm{mmHg}$ & 2 \\
\hline 3 & $100 \%$ @ 50pps & $50 \%$ & $105 \mathrm{~cm}, 40 \mathrm{cc} / \mathrm{min}, 600 \mathrm{mmHg}$ & 3 \\
\hline 4 & $100 \%$ @ 50pps & $70 \%$ & $105 \mathrm{~cm}, 40 \mathrm{cc} / \mathrm{min}, 650+\mathrm{mmHg}$ & 3 \\
\hline
\end{tabular}

pps $=$ pulses per second

Table 2. NeoSoniX settings for each cataract grade.

\begin{tabular}{|c|c|c|c|c|}
\hline Grade & Fixed Burst & $\begin{array}{c}\text { NeoSoniX } \\
\text { Amplitude }\end{array}$ & Fluidics - fixed flow \& vacuum & Dynamic Rise \\
\hline 1 & $25 \%, 50 \mathrm{~ms}$ & $50 \%$ & $60 \mathrm{~cm}, 36 \mathrm{cc} / \mathrm{min}, 400 \mathrm{~mm} \mathrm{Hg}$ & 3 \\
\hline 2 & $30 \%, 20 \mathrm{~ms}$ & $60 \%$ & $90 \mathrm{~cm}, 40 \mathrm{cc} / \mathrm{min}, 550 \mathrm{~mm} \mathrm{Hg}$ & 3 \\
\hline 3 & $50 \%, 20 \mathrm{~ms}$ & $70 \%$ & $90 \mathrm{~cm}, 40 \mathrm{cc} / \mathrm{min}, 600 \mathrm{~mm} \mathrm{Hg}$ & 3 \\
\hline 4 & $70 \%, 80 \mathrm{~ms}$ & $80 \%$ & $100 \mathrm{~cm}, 40 \mathrm{cc} / \mathrm{min}, 650+\mathrm{mm} \mathrm{Hg}$ & 4 \\
\hline
\end{tabular}

Table 3. Status of the cornea on the first postoperative day in AquaLase and NeoSonix groups.

\begin{tabular}{|l|c|c|c|c|}
\hline \multirow{2}{*}{ Status of cornea } & \multicolumn{2}{|c|}{ AqL } & \multicolumn{2}{c|}{ NS/U } \\
\cline { 2 - 5 } & eyes & $\%$ & eyes & 94 \\
\hline $\begin{array}{l}\text { crystal clear, no trace } \\
\text { of striae or edema }\end{array}$ & 48 & 96 & 37 & 6 \\
\hline $\begin{array}{l}\text { mild epithelial edema } \\
\text { and striae }\end{array}$ & 2 & 4 & 3 & \\
\hline
\end{tabular}

$\mathrm{AqL}=$ AquaLase

$\mathrm{NS} / \mathrm{U}=$ NeoSoniX

BCVA improved in all eyes and was 20/25 or better (1.0 to 0.8 ) immediately after operation. The cornea was crystal clear (no trace of striae or edema) in 48 eyes (96\%) in the AquaLase group and in 47 eyes (94\%) in the NeoSoniX group on the first postoperative day (Table 3).

\section{DISCUSSION}

The art and science of cataract removal through Kelman ultrasonic phacoemulsification ${ }^{12,13}$ is constantly evolving - continual improvements in phaco technique and technology have made the procedure more safe and efficient than was possible in the past. Surgeons need to encorporate new developments to achieve the greatest possible patient benefit.

The Infiniti Vision System (Alcon Laboratories, Fort Woth, Texas) is the newest addition to the Alcon line of phacoemulsification instruments. It offers various options for lens removal, including traditional ultrasound, NeoSoniX and AquaLase. NeoSoniX was originally introduced as an upgrade of the Alcon Legacy and in addition to conventional US phacoemulsification, the NeoSoniX option adds oscillations up to 2 degrees at an approximate frequency $100 \mathrm{~Hz}$. The addition of oscillattory movement improves surgeon control and occlusion management, enhances cutting performance, allowing lower energy production with resultant lower risk of intraoperative damage and better surgical outcomes ${ }^{11,14}$.

Rather than using mechanical US energy from a vibrating phaco needle, the AquaLase handpiece uses warmed pulses of balanced salt solution (BSS) to emulsify the lens material for aspiration ${ }^{15,16}$. AquaLase offers the advantage of potentially reducing the risk of damage to intraocular tissues because the fluid pulses are quickly dampened in the eye's fluid environment. The attenuation effect very rapidly spreads elsewhere in the eye - there is no radiating ultrasonic pressure wave. The other fundamental difference between AquaLase and conventional US phacoemusification is that there is no possibility of incision burn from AquaLase. In conventional US lens removal, thermal tissue damage at the incision site is a potential complication with significant sequellae ${ }^{17,18}$. The solution used by AquaLase is warmed to $57^{\circ} \mathrm{C}$, and experimental measurement of internal wound temparature has shown that no incision heat is generated even at full power ${ }^{16}$. The softer AquaLase tip is more capsule friendly and there is 
decreased risk of rupture of the posterior capsule. In this limited series we have not seen any of this intraoperative complication.

We have been using the Infiniti Vision System since July 2004. We now routinely use only NeoSoniX or AquaLase in $100 \%$ of our cases. Based on our own experience, there is a short learning curve for the experienced US phacoemulsification surgeon in adopting AquaLase. We perform routinely quick-chop technique when using NeoSoniX. We have found that AquaLase liquefaction is performed more efficiently with prechopping of the nucleus. Once the pieces are created - whether by grooving, chopping or prechopping, we found it beneficial to remove them with as little motion of the tip as possible. This was achieved by using fixed flow and fixed vacuum to optimize occlusion.

Both AquaLase and NeoSoniX proved to be safe and efficient for cataract removal in our survey. There was minimal change in corneal thickness after surgery with the results slightly better in the AquLase group. There was no significant loss of the endothelial cells in either groups.

The only limitation of AquaLase that we have found is that it is not as effective as NeoSoniX in the case of harder cataracts (grade 4 and 5). With these harder lenses, the NeoSoniX use of axial US energy coupled with oscillations of the tip appears more effective. AquaLase easily extracts all cataracts of grade 1 and 2 . With prechopping of the nucleus, AquaLase is also able to efficiently remove dense cataracts of grade 3 and many of grade 4 . For those cases, where lens density was too hard for efficient AquaLase use, we were able to easily transition to the NeoSoniX handpiece with minimal effort.

One of the reasons we suspect that AquaLase is so successful is through the impressive fluidics of the Infiniti Vison System. We found we were able to safely use high vacuums (400 to $650+\mathrm{mm} \mathrm{Hg}$ ) and high flow rates ( $40 \mathrm{~mL} / \mathrm{min}$ ) with full occlusion of the aspiration port.

The AquaLase is one of the most promising new technologies available today and the techniques for its use are still evolving. Because it is exceedingly difficult to rupture the posterior capsule while using AquaLase, this modality is excellent for polishing the capsule and removing lens epitelial cells. AquaLase is especially well suited to refractive lens procedures and pediatric cataracts. With prechopping of the nucleus we now use AquaLase in $60-70 \%$ of our cataract cases in which we are removing even hard and dense nuclei.

\section{CONCLUSUION}

In conclusion, the results of our bilateral 50 patient study demonstrated that both Infiniti AquaLase and NeoSoniX modalitis using the Infiniti Vision System provided similar high-quality post-operative results There was a statistical significant difference in the postoperative changes for pachymetry with better results in AquaLase group using the Wilcoxon Signed-Rank Test one month later. The inherent design of AquaLase essentially eliminates the possibility of wound site thermal injury. The softer tip is more capsule friendly. Since our study appears to show that AquaLase provides similar and perhaps slightly improved outcomes, it is a method we try to use on all cataracts of grades $1-3$. We believe this new techology minimizes intraoperative damage to ocular structures and maximizes the level and rapidity of visual rehabilitation.

\section{ACKNOLWEDGEMENTS}

Supported in part by research project MZO 00179906

from the Ministry of Health, Prague, Czech Republic

Josef Kvasnicka, M.Sc. did the statistical analysis.

\section{REFERENCES}

1. Davison JA. Introduction to phacoemulsification. In: Koch PS, Davison JA, editors. Textbook of Advanced Phacoemulsification Techniques. Thorofare, NJ: Slack Inc; 1991. p. 107-138

2. Buratto L, editor. Phacoemulsification. Principles and Techniques. Thorofare, NJ: Slack Inc; 1998. p. 3-21

3. Gimbel HV, Neuhann TMD. Development, advantages, and methods of the continuous circular capsulorrhexis technique. J Cataract Refract Surg. 1990;16:3137

4. Boyd B. The Art and the Science of Cataract Surgery. Bogota,Colombia: Highlights of Ophthalmology Int'1; 2001. p. 409-411

5. Gimbel HV. Divide and conquer nucleofractis phacoemulsification: development and variations. J Cataract Refract Surg. 1991; 17:28-29

6. Braga-Mele R, Hhan BU. Hydro-chop technique for soft lenses. J Cataract Refract Surg. 2006; 32:18-21

7. Fine IH. The choo-choo chop and flip phacoemulsification technique. In: Fine IH, editor. Clear Corneal Lens Surgery. Thorofare, NJ: Slack Inc; 1999. p. 71-83

8. Fine IH, Packer M, Hoffman RS. Use of power modulations in phacoemulsification; choo-choo chop and flip phacoemulsification. J Cataract Refract Surg. 2001; 27:188-197

9. Fine IH, Packer M, Hoffman, RS. New phacoemulsification technologies. J Cataract Refract Surg. 2002; 28:1054-1060

10. Fine IH, Packer M, Hoffman RS. Power modulations in new phacoemulsification technology; improved outcomes. J Cataract Refract Surg. 2004; 30:1014-1019

11. Vasavada AR, Shetar MR, Yooi CL. NeoSoniX ultrasound versus ultrasound alone for phacoenulsification. J Cataract Refract Surg. 2004; 30:2332-2335

12. Banko A, Kelman CD, inventors; Cavitron Corporation assignee. US patent 3589 363. July 25,1967

13. American Society of Cataract and Refractive Surgery Interview. History in the making: in tune with the father of phacoemulsification. J Cataract Refract Surg. 1997; 23:1128-1129

14. Jiraskova N, Rozsival P. Phacoemulsification parameters: Series 20000 Legacy Versus Legacy with AdvanTec software and NeoSonix handpiece. J Cataract Refract Surg. 2004; 30:144-148

15. Hoffman RS, Fine IH, Packer M. New phacoemulsification technology. Curr Opin Ophthalmol. 2005; 16:38-43

16. Mackool RJ, Brint SF. AquaLase: a new technology for cataract extraction. Curr Opin Ophthalmol. 2004; 15:40-43

17. Bissen-Miyajima H, Shimmura S, Tsubota K. Thermal effect on corneal incisions with different phacoemulsification ultrasonic tips. J Cataract Refract Surg. 1999; 25:60-64

18. Mackool RJ. Incision burns. J Cataract Refract Surg. 2003; 29:233-235 